\title{
Intent to Stay in Nursing Profession and Associated Factors Among Nurses Working in Public Hospitals of Harari Regional State and Dire Dawa Administration, Eastern Ethiopia
}

\author{
Kirubel Eshetu ( $\sim$ kiruesha2@gmail.com ) \\ Wolaita Sodo University \\ Belete Gelaw \\ Wolaita Sodo University \\ Tadele Lankrew \\ Wolaita Sodo University \\ Tiwabwork Tekalegn \\ Wolaita Sodo University \\ Andualem Assefa \\ Wolaita Sodo University \\ Tsegaye Demeke \\ Wolaita Sodo University
}

\section{Research Article}

Keywords: Intent to Stay, Nurse, Profession, Public Hospitals, Harar, Dire Dawa, Eastern Ethiopia

Posted Date: June 2nd, 2021

DOl: https://doi.org/10.21203/rs.3.rs-538730/v1

License: (c) (i) This work is licensed under a Creative Commons Attribution 4.0 International License.

Read Full License 


\section{Abstract}

Background: Intent to stay in nursing profession becomes a critical issue across a globe and lack of nurses represent problems of health care system in terms of cost, ability to care for patients and quality of care. Many nurses are departing from their profession. There is scarce data about the level and factors associated with intent to stay.

Objective: To determine the level of intent to stay in nursing profession and associated factors among nurses working at public hospitals of Harari regional state and Dire Dawa Administration, Eastern Ethiopia.

Methods: Institutional based cross-sectional study was conducted among 413 nurses working in public hospitals, Harar and Dire Dawa Administration from March 1 to 30/2020. Participants were selected by simple random sampling methods. Interviewer guided pre-tested and structured self-administered questionnaire were used to collect data. Data were entered using EpiData Version 4.6 and exported to SPSS Version 20 for analysis. Descriptive statistics were carried out. Bivariable and multivariable analysis were used. The association between dependent and independent variables was determined using adjusted odds ratio with $95 \%$ confidence interval. Finally, the variables that have $p$-value of $<0.05$ were considered as statistically significant. Goodness of fit was tested by Hosmer Lemeshow statistic which was 0.254 and omnibus test, which was 0.00 .

Results: The results showed that level of Nurses' intent to stay in the profession was $49.3 \%$ (95\% Cl: $46-$ 55.9). Having dependent family members ( $A O R=1.908,95 \% \mathrm{Cl}: 1.142-3.188$ ), overall job satisfaction $(A O R=6.54,95 \% \mathrm{Cl}, 2.774-15.41)$ and overall organizational commitment (AOR=0.301, 95\% $\mathrm{Cl}, 0.127-$ $0.713)$ and normative commitment $(\mathrm{AOR}=3.617,95 \% \mathrm{Cl}, 1.879-6.963)$ were significantly associated with intent to stay.

Conclusion: This study showed that the level of intent to stay was low among nurses. Having dependent family members, job satisfaction, organizational commitment and having a high normative commitment showed association with intent to stay. This kind of instability in nursing staffs might compromise the nursing service quality. Therefore, enhancing nurses' job satisfaction, autonomy, professional opportunity, and organizational commitment are key for improving nurse's intent to stay.

\section{Background}

Intent to stay (ITS) is defined as "the nurses decision to remain in nursing profession before retirement" (1). Nurses retention refers to the interest to keep nurses in their hospitals and profession (2). Evidence in the literature revealed that Nurses shortage is defined as not only shortage of qualified professionals but also the inability of experienced nurses to stay in their profession until retirement (3). The future of professional nursing is threatened today by the current and impending shortage of experienced nurses to stay in nursing profession (4). According to world health organization (WHO) there is a shortage of 7.2 
million health workers with regard to health needs, whereas report by the third global forum on human resources for health estimates that by 2035 , the nursing deficit will reach 12.9 million (4-6).

The shortage of experienced nurses become a critical issue across the globe, especially in sub-Saharan Africa countries, nurse population ratio is 0.65 per 1000 population which is lower than the WHO standards which is 2.28 (7). Global nursing shortage negatively affects the quality of care and patient waiting time, the shortage can be reduced by retaining nurses in profession until retirement (8).

Studies conducted in Amhara and Oromia regions, Ethiopia were $39.8 \%$ and $57.75 \%$ respectively which indicated low level of intention to stay in nursing profession (9-11).

Currently there are a lot of factors which contributing for increased demand of nurses like increase aging population, presence of complex disease, new infectious disease, road traffic injuries and remerging once, globalization and high public trust for nurses are some of them (12). Shortage of experienced nurses are closely linked to increased mortality and morbidity, accident/injuries, cross infection and adverse postoperative events(poor patient outcome, increased cost of care); overall it harts health care systems, quality of care, patients and staff (13).

The poor retention a policy, ineffective use of available nursing resource through inappropriate skill mix, poor incentive structure, low professional opportunity, unpaid overtime, work load, poor nurses physician communication, presence of violence against nurses and inadequate career support often lead to leave the profession and intensify the shortage of nurse (3). The nurse job satisfaction, work group cohesion and collaboration, characteristics of nurse, manager ability and support, low level of burnout and organizational commitment are among the factors positively associated with intent to stay in the profession $(11,14)$

Previous studies focused on magnitude of turnover of Nurses and a few studies conducted related to intent to stay in nursing profession in the country and no recent data regarding this in the study area in particular. Therefore, this study is intended to determine the level of intention to stay and associated factors among nurses working at public hospitals of Harari Regional state and Dire Dawa administration, Eastern Ethiopia.

\section{Methods}

\section{Study setting and Period}

The study was conducted in four public hospitals found in Harar and Dire Dawa Administration, Eastern Ethiopia. Harar town is the capital city of Harari region located at $526 \mathrm{Kms}$ away from Addis Ababa. There are two public hospitals namely, Hiwot Fana Specialized University hospital and Jugal hospital. Dire Dawa Administration is located at $515 \mathrm{Kms}$ from the capital city of Ethiopia, Addis Ababa. In the administration, there are two governmental and four private hospitals and eight health centers. For this 
study two public hospitals were selected: These are Dilchora referral hospital and Sabiyan primary level hospital. The study was conducted from March 1 to $30 / 2020$.

\section{Study Design and Population}

Institutional based cross-sectional study design was employed among 413 Nurses working in four selected hospitals in Harar and Dire Dawa Administration.

All employed Nurses who are working at public hospitals were the source population and those Nurses working in the four public hospitals and available during the data collection period were study population. Nurses who were not available during the time of the study period due to annual, maternal, sick, study leave and newly employed in the last six months were excluded.

\section{Sample Size Determination and Sampling Technique}

The sample size was calculated by using single population proportion formula with the following assumptions: The proportion of intent to stay $(P)$ was $57.75 \%(10)$, standard normal distribution $(z=1.96)$, $5 \%$ margin of error(d)

$$
\mathrm{n}=\frac{(\mathrm{z} \mathrm{\alpha} / 2)^{2} \mathrm{p}(1-\mathrm{p})}{\mathrm{d}^{2}}=\frac{(1.96)^{2} \times 0.5775(1-0.5775)}{(0.05)^{2}}=\frac{0.93733}{0.0025}=375
$$

Then by adding a 10\% non-response rate the final sample size becomes 413 .

Where: $\mathrm{n}=$ minimum sample size required for the study.

$z=$ standard normal distribution $(z=1.96)$ with confidence interval of $95 \%$.

$p=$ proportion of intent to stay among nurses $(p=57.75 \%)(10)$.

$d=$ is tolerable margin of error $(d=0.05)$.

Four hospitals were purposively selected because they have higher numbers of nurses' population. The sample size was proportionally allocated to selected hospitals. Finally, simple random sampling technique was employed with the lottery method to recruit the study participants from each hospital.

\section{Data Collection Procedures}

An interviewer guided self-administered structured questionnaire which was developed in English language was used to collect data. Participants were identified by using attendance sheets from 
respective wards then questionnaire was given to them after brief introduction of the aim of study. The questionnaire was collected back on the same day. The questionnaire was adopted and modified from previous different literatures $(9,10)$. The questionnaires address the nurses' socio-demographic characteristics such as age, gender, marital status, work experience, job position, level of education, current area of practice, wards and having dependent family members, job satisfaction, intent to stay, autonomy, professional opportunity and organizational commitment. Intent to stay was measured by a scale created from six items. The items were answered on a five-point Likert scale with response options ranging from 1 (strongly disagree) to 5 (strongly agree). Similarly, job satisfaction was measured by $37-$ item scale with 5 subscales: autonomy and professional opportunities, scheduling, support, relationship and interaction and pay and benefits. These items were also answer on a 5-point Likert scale with response options ranging from 1 (very dissatisfied) to 5 (very satisfied). In the same manner, organizational commitment was measured by 22 -item scale with 3 subscales. Affective, continuance and normative commitment. In the same way, the items were answer on a 5-point Likert scale with response options ranging from 1 (strongly disagree) to 5 (strongly agree).

Data quality was assured through Pre-test was done on 5\% (21 participants) of the sample at Haramaya hospital, eastern Ethiopia with some time gap before the actual data collections and the amendment was made accordingly. One day training was given by principal investigators to the data collectors and supervisors prior to data collection. The training was focused on the objective of the study, understanding the meaning of each question, obtaining consent, keeping the confidentiality of the information they gathered and quality of data collection. Emphasis was given on the significance and the meanings of each question as well as how to explain for the participants incomprehensible manner if required. On top of this, supervisors were followed by data collectors and the principal investigator was also checked for the collected data clarity, accuracy and completeness on a daily basis. Double data entry was made.

\section{Data Processing and Analysis}

Cleaned data were coded and entered to EpiData 4.6 version and exported to SPSS windows version 20 for analysis. At the beginning of the analysis, scores for intent to stay; and each subscales of job satisfaction and organizational commitment were created by summation of the score's statements include within each sub-scale. Descriptive analyses were done. Then the variables were re-coded and dichotomized. The descriptive findings were presented by tables and graphs.

The responses of the outcome variable were first added and overall mean were computed. Then, it was categorized as yes and no for the respective value of greater than and less than the mean. The job satisfaction and organizational commitment related factors were computed Then, the recoded score was added for each participant and an overall mean were computed. Finally, they were categorized and recoded as satisfied and dissatisfied for job satisfaction items and the rest high and low for organizational commitment items for a score of greater than and less than the mean respectively. 
Bivariable analyses were computed to check association between dependent and each independent variable using binary logistic regression. All variables with $p \leq 0.25$ in the bivariable analysis were included in the final model of multivariable analysis in order to control all possible confounders. Multi colinearity test was carried out to see the correlation between independent variables by using standard error and co-linearity statistics (VIF > 10 and standard error $>2$ was considered as suggestive of existence of multi co-linearity). The degree of association between independent and dependent variables were assessed by using adjusted odds ratio with $95 \%$ confidence interval. P-value less than or equal to 0.05 were considered as statistically significant. The goodness of fit was tested by Hosmer-Lemeshow statistic which was insignificant and omnibus test, which was significant.

\section{Operational Definitions}

Have intent to stay: nurses' decision to stay in their profession which was measured by six items in nursing profession having a five-point Likert scale ranging from six to thirty with a mean score of 18.2 and higher than 18.2 score nurses considered as having intention to stay in nursing profession.

Satisfied: Nurses who scored $>60 \%$ of the sum of the satisfaction scales.

High commitment: Nurses who score $>60 \%$ of the sum of the commitment scales.

\section{Results}

A total of 413 study participants were involved of which, 404 completely filled an interviewer guided selfadministered questionnaire, making a response rate of $97.82 \%$. More than half, $221(54.7 \%)$ of the study participants were males. The participants ages ranged from 20-49 years with a mean ( \pm ) age of 28.91 ( \pm 5.541 SD) years. About half of participants 210(52.0\%) were single. Most of the respondents $360(89.1 \%)$ were staff nurses and almost half of them 205(50.7\%) had no dependent family members. The length of service year of participants ranged from half year to twenty-seven years with a mean $( \pm)$ of $5.0( \pm 4.3 \mathrm{SD})$ service years. The majority, 275(68.1\%) of the participants were found within the work experience category of $0.5-5$ years. Nearly to three quarters, $283(70 \%)$ of the participants were BSc degree holders (Table1).

\section{Level of Intent to Stay in Nursing Profession}

The mean $( \pm S D)$ score for the level of intent to stay in nursing profession among nurses was $18.2( \pm 4.2)$ and in this study the level of intent to stay in nursing profession was $49.3 \%(95 \% \mathrm{Cl} 46.0-55.9)$ and the remaining $50.7 \%$ of nurses had intention to leave the profession (Figure1). 


\section{Job Satisfaction and Organizational Commitment Related Characteristics of Participants}

In terms of overall job satisfaction more than half 210 (52\%) of participants were satisfied and 204 (50.5\%) of participants had a low organizational commitment. In each subscale of the job satisfaction majority of nurses were satisfied with scheduling, support, payment and other benefits $(55.2 \%, 57.2 \%$, $57.2 \%)$ respectively. More than half of them 209 (51.7\%) were satisfied with autonomy and professional opportunity.

On the other hand, majority of the respondents 210 (52\%) were dissatisfied with relationship and interaction. More than half 23 (55.2\%), 231 (57.2\%), and 231 (57.2\%) were satisfied with scheduling, support, pay and benefits respectively. However, a quite above half of nurses 210 (52\%) were dissatisfied with relationship and interaction. On the organizational commitment aspects more than average of nurses had low affective and continuance commitment 216 (53.5\%) and $212(52.5 \%)$ respectively. On the contrary, the majority of 245 (60.6\%) of nurses had high normative commitment (Table2).

\section{Factors associated with Intent to Stay in Nursing Profession Among Nurses}

Eighty variables were entered for bivariate logistic regression. Among those current work place (ward), educational status, job position and scheduling were failed to pass from the bivariate analysis because their $p$-value were greater than 0.25 . The rest variables, then were entered in the final model of multivariate logistic regression.

In multivariate analysis the following variables had shown statistical significance: having dependent family members, overall job satisfaction, overall organizational commitment and normative commitment were the significant predictors (Table3).

\section{Discussion}

Nurses are the key in achieving the WHO, CDC, United Nations sustainable development goals, strategies and overall to achieve desired quality of patient outcome and also, nursing is a high risk and a highpressure profession. In the health care setting majority of the tasks are conducted by nurses But, most of the role of nurses is hidden within physician shadow and considering them as physician slaves this issue reduces the values of nurses which makes them less intent to stay.

Hence making nurses to stay in their profession and identifying positive energy which inspires it and making nurses to love nursing and wholehearted engagement is the obligation of every concerned body. The continuous departure of nurses from the profession by different reasons, especially due to job satisfaction with work related values, socio-demographic factors and organizational commitment factors 
resulted in hurting the overall quality of healthcare systems. So, this study came-up with these perspectives as summarized below:

The overall results of this study showed that the level of intent to stay in nursing profession was $49.3 \%$ $(95 \% \mathrm{Cl} 46.0$ - 55.9). This study identified that having dependent family members, satisfaction with job, high overall organizational commitment and normative commitment were found to be the potential predictors of intent to stay.

The magnitude of intent to stay in the nursing profession was $49.3 \%$ indicating low. This finding is slightly lower than studies done in Jimma zone, Ethiopia (10) and Thailand (63.6\%) (15), Hungary (50.8\%) (16), Italy (66.9\%) (17), Canada (77.9\%) (2). However, it was higher than study conducted in Amhara region, Ethiopia (9).This difference might be due to the presence of less payment and poorer organizational support in the context of current study. The job satisfactions and organizational commitment in other countries might be better in terms of providing opportunity for professional development, attractive salary and incentives, risk allowance, having a clear role and responsibility, vision and mission that the nurses believe and strong organizational support for nurses.

On the other hand, this magnitude was a little bit higher than an Ireland study (40\%) (18), Korea study (32.8\%) (19). This could be due to limited availability of alternative jobs and increased perceived cost which may lead the Ethiopian nurses to develop normative commitment.

The overall results of this study showed that the level of intent to stay in nursing profession was low. According to this study the sociodemographic characteristics like having dependent family members had a significant relationship. The finding also indicated that overall job satisfaction was significantly associated with intent to stay. Related to the organizational commitment overall commitment and among items normative commitment were found to be the significant predictors of intent to stay in nursing profession among nurses.

Having Dependent family members was one of the significant predictors of nurse socio-demographic variables in that made them less reluctant to leave the profession than those participants who didn't have dependent family members. This finding is consistent with a Thailand study (15) that having dependent family members could encourage to prefer stability rather than leaving profession.

Job satisfaction was another predictor variable. This finding is inline and also supported by study conducted at Amhara region and Jimma zone, Ethiopia, which found that nurses who were satisfied in autonomy, professional opportunity, relationship and interaction, support, scheduling, payment and others benefits were the potential associated factors which had a direct impact on intent to stay $(9,10$, 20). It was also consistent with many other similar studies in that job satisfaction had frequently been reported as the most common predictors of nurses who decided intent to stay $(15,21-26)$. These could indicate that nurses who had opportunities for professional development and got relatively better payment and benefit receive which is proportional to the amount of task they perform; good relation with 
staff, good supporting then the nurses' level of intent to stay in nursing profession will increase and also it is a vital factor.

Another significant predictor of intent to stay were nurses who were with high overall organizational commitment and normative commitment remained in the profession. The nurses with the feeling of obligation to remain within an organization or had a high normative commitment more likely intent to stay in the profession. The finding agreed with the findings of other studies $(1,16,27)$. It may be due to most of my study participants were with in work experience category of 0.5 - 5yrs, so they feel that they have an obligation to stay in their organization and as well as in the profession.

\section{Conclusions}

Intent to stay in the nursing profession among nurses working in public hospitals of the Harari regional state and Dire Dawa administration is low. Overall job satisfaction, having dependent family members, overall organizational commitment and having a high normative commitment were the most prominent factors with the intent to stay in the nursing profession.

\section{Abbreviations}

AOR: Adjusted odds ratio CDC: communicable disease controls Cl: Confidence Interval COR: Crude odds ratio ITS: intent to stay RGs: registered nurse SD: standard deviation WHO: world health organizations.

\section{Declarations}

\section{Ethics Approval and Consent to Participate}

The study was conducted after obtaining ethical clearance from Haramaya University College of health and medical sciences institutional health research ethical review committee through ethical letter with protocol number $0437 / 2020$, written on February 18,2020 . The study was also done as per the declaration of Helsinki. The Letter was provided to each hospital administrative body to get their informed consent for data collection before starting to collect data. An informed written consent was obtained from the study participants after the purpose and procedures of study was fully informed. Prior to administering the questionnaires, the objectives of the study were clearly explained, informed voluntary written and signed consent were obtained. Confidentiality was ensured. To keep the anonymity of study participants, code numbers rather than personal identifiers will be used. Moreover, confidentiality of data was kept at all levels of the study and not used for any other purposes than the stated study objectives.

\section{Consent for Publication}

This part is not applicable because the manuscript contains no any individual person's data in any form (including individual details, images or videos). 


\section{Availability of Data and Materials}

All data and materials in this manuscript are available from the corresponding author on reasonable request.

\section{Competing Interests}

The authors declare that they have no competing interests.

\section{Funding}

Not applicable

\section{Authors' Contributions}

$\mathrm{KE}$ : involved in designing of the study, data collection, data analysis, drafting and critically reviewing the manuscript. BG, AA, TL, TT, \& TD: Originating research concept, involved in designing of the study, analysis of the data and critically reviewing the manuscript. All authors read and approved the final manuscript.

\section{Acknowledgments}

We would like to express our heartfelt gratitude to all selected study site officials whom we have communicated, and indorsed as to conduct this study. Our special thanks also extended to the study participants, data collectors, supervisors, and staffs.

\section{References}

1. Wang L, Tao H, Ellenbecker C, Liu X. Predictors of hospital nurses' intent to stay: a cross-sectional questionnaire survey in Shanghai, China. International Nursing Review. 2012;59(4):547-54.

2. Zeytinoglu IU, Denton M, Davies S, Baumann A, Blythe J, Boos L. Retaining nurses in their employing hospitals and in the profession: effects of job preference, unpaid overtime, importance of earnings and stress. Health Policy. 2006;79(1):57-72.

3. Buchan J, Duffield C, Jordan A. 'Solving'nursing shortages: do we need a New Agenda? Journal of Nursing Management. 2015;23(5):543-5.

4. Albaugh JA. Keeping nurses in nursing: the profession's challenge for today. Urologic Nursing. 2003;23(3):193-9.

5. Truth AU. No Health without a workforce. World Health Organisation (WHO) Report. 2013.

6. WHO. Global strategy on human resources for health: workforce 2030. 2016. 
7. Scheffler RM, Mahoney CB, Fulton BD, Dal Poz MR, Preker AS. Estimates Of Health Care Professional Shortages In Sub-Saharan Africa By 2015: Critical shortages of health workers are projected in 2015 throughout sub-Saharan Africa, and the projected cost to eliminate them approaches \$20 billion. Health affairs. 2009;28(Suppl1):w849-w62.

8. Ujvarine AS, Zrinyi M, Toth H, Zekanyne IR, Szogedi I, Betlehem J. Intent to stay in nursing: internal and external migration in Hungary. Journal of clinical nursing. 2011;20(5-6):882-91.

9. Engeda $\mathrm{EH}$, Birhanu AM, Alene KA. Intent to stay in the nursing profession and associated factors among nurses working in Amhara Regional State Referral Hospitals, Ethiopia. BMC nursing. 2014;13(1):24.

10. Gizaw A, Lema T, Debacho W, Geremossa G. Intention to Stay in Nursing Profession and Its Predictors among Nurses Working in Jimma Zone Public Hospitals, South West Ethiopia. J Nurs Care. 2018;7(440):2167-1168.1000440.

11. Labrague LJ, Gloe D, McEnroe DM, Konstantinos K, Colet P. Factors influencing turnover intention among registered nurses in Samar Philippines. Applied Nursing Research. 2018;39:200-6.

12. Idai C. Public health round-up. Bull World Health Organ. 2019;97:312-3.

13. Oulton JA. The global nursing shortage: an overview of issues and actions. Policy, Politics, \& Nursing Practice. 2006;7(3_suppl):34S-9S.

14. Tourangeau AE, Cummings G, Cranley LA, Ferron EM, Harvey S. Determinants of hospital nurse intention to remain employed: broadening our understanding. Journal of advanced nursing. 2010;66(1):22-32.

15. Lwin PM, Rattanapan C, Laosee O. Nurses' intention to remain employed in hospitals: Understanding the shortage in the context of Myanmar. International journal of nursing practice. 2017;23(4):e12536.

16. Wagner CM. Organizational commitment as a predictor variable in nursing turnover research: literature review. Journal of advanced nursing. 2007;60(3):235-47.

17. Sasso L, Bagnasco A, Catania G, Zanini M, Aleo G, Watson R, et al. Push and pull factors of nurses' intention to leave. Journal of nursing management. 2019.

18. McCarthy G, Tyrrell MP, Lehane E. Intention to'leave'or'stay'in nursing. Journal of nursing management. 2007;15(3):248-55.

19. WeiBo Z, Kaur S, Jun W. New development of organizational commitment: A critical review (19602009). African Journal of Business Management. 2010;4(1):012-20.

20. Ayalew F, Kols A, Kim Y-M, Schuster A, Emerson MR, Van Roosmalen J. Factors affecting turnover intention among nurses in Ethiopia. World Health Popul. 2015;16(2):62-74.

21. Wafaa AE. Professional Identity and Turnover Intention among Staff Nursesin Different. IOSR Journal of Nursing and Health Science (IOSR-JNHS) e-ISSN: 2320-1959 p-ISSN: 2320-1940 Volume 6, Issue 3 Ver III (May-June 2017), PP 00-00. 2017.

22. Yarbrough S, Martin P, Alfred D, McNeill C. Professional values, job satisfaction, career development, and intent to stay. Nurs Ethics. 2017;24(6):675-85. 
23. Liu C, Zhang L, Ye W, Zhu J, Cao J, Lu X, et al. Job satisfaction and intention to leave: a questionnaire survey of hospital nurses in Shanghai of China. Journal of clinical nursing. 2012;21(12):255-63.

24. Halcomb E, Bird S. Job Satisfaction and Career Intention of Australian General Practice Nurses: A Cross-Sectional Survey. Journal of Nursing Scholarship. 2020.

25. Bloxsome D, Ireson D, Doleman G, Bayes S. Factors associated with midwives' job satisfaction and intention to stay in the profession: An integrative review. Journal of clinical nursing. 2019;28(34):386-99.

26. Karlsson AC, Gunningberg L, Bäckström J, Pöder U. Registered nurses' perspectives of work satisfaction, patient safety and intention to stay-A double-edged sword. Journal of nursing management. 2019;27(7):1359-65.

27. Lee MA, Ju YH, Lim SH. A Study on the Intent to Leave and Stay among Hospital Nurses in Korea: A cross sectional survey. Journal of Nursing Management. 2019.

\section{Tables}

Table1: Socio-demographic characteristics of nurses working at public hospitals of Harari Regional State and Dire Dawa Administration, Eastern Ethiopia, 2020. 


\section{Variables \\ Frequency(N) Percent (\%)}

Gender

Male

221

54.7

Female

183

45.3

\section{Age category}

20-29

248

61.4

30-39

136

33.7

40-49

20

5.0

Categorization of working experience(yrs.)
$0.5-5$
275
68.1
6-10
91
22.5
11-15
27
6.7
$>15$
11
2.7

Current work place/ward

Medical ward

94

23.3 


\begin{tabular}{lcc} 
Surgical ward & 87 & 21.5 \\
\hline Outpatient department & 94 & 23.3 \\
\hline Pediatrics ward & 73 & 18.1 \\
\hline Others* & 56 & 13.9
\end{tabular}

Educational level

Diploma

BSc degree

MSc degree

Marital status

Married

200

49.5

Single

204

50.5
114
28.2

70.0

1.7

7
49.5

$204 \quad 50.5$

Job position

Staff nurse

Nurse staff manager

Dependent family member

360

89.1

44

10.9 


\begin{tabular}{lll} 
Have & 199 & 49.3 \\
\hline Not have & 205 & 50.7
\end{tabular}

*MCH, Gyne, Psychiatric clinic, ophthalmic clinic.

Table 2: Job satisfaction and organizational commitment characteristics of participants who were currently working in public hospitals of Harari Regional State and Dire Dawa Administration, Eastern Ethiopia, 2020. 


\begin{tabular}{|ll|}
\hline Variables & Frequency (\%) \\
\hline Job satisfaction & \\
\hline Dissatisfied & $294(48 \%)$ \\
\hline Satisfied & $210(52 \%)$ \\
\hline Autonomy and professional opportunity & \\
\hline Dissatisfied & $195(48.3 \%)$ \\
\hline Satisfied & $209(51.7 \%)$ \\
\hline Scheduling & \\
\hline Dissatisfied & $181(44.8 \%)$ \\
\hline Satisfied & $223(55.2 \%)$ \\
\hline Support & \\
\hline Dissatisfied & $173(42.8 \%)$ \\
\hline Satisfied & $231(57.2 \%)$ \\
\hline Relationship and interaction & \\
\hline Dissatisfied & $212(52.5 \%)$ \\
\hline Satisfied & $192(47.5 \%)$ \\
\hline Pay and benefit & $216(52 \%)$ \\
\hline Dissatisfied & $194(48 \%)$ \\
\hline Satisfied & $204(50.5 \%)$ \\
\hline Organizational commitment & \\
\hline Low & \\
\hline High & \\
\hline Affective commitment & \\
\hline Low & \\
\hline High & \\
\hline Continuance commitment & \\
\hline Low & \\
\hline High & \\
\hline
\end{tabular}




\begin{tabular}{|ll|}
\hline Low & $159(39.4 \%)$ \\
\hline High & $2455(60.6 \%)$ \\
\hline
\end{tabular}

Table3: Factors associated with Intent to Stay in Nursing Profession Among Nurses among nurses working at public hospitals of Harari region and Dire Dawa administration, Eastern Ethiopia. 


\begin{tabular}{|c|c|c|c|c|}
\hline \multirow[t]{2}{*}{ Variables } & \multicolumn{2}{|l|}{ ITS } & \multirow[t]{2}{*}{ COR $(95 \% \mathrm{Cl})$} & \multirow[t]{2}{*}{ AOR $(95 \% \mathrm{Cl})$} \\
\hline & $\begin{array}{l}\text { Yes } \\
(\%)\end{array}$ & $\begin{array}{l}\text { No } \\
\text { (\%) }\end{array}$ & & \\
\hline \multicolumn{5}{|l|}{ Gender } \\
\hline Male & $101(45.7)$ & $120(54.3)$ & 1.00 & \\
\hline Female & $98(53.6)$ & $85(46.4)$ & $\begin{array}{l}1.307(0.925- \\
2.029)\end{array}$ & $\begin{array}{l}1.482(0.922- \\
2.380)\end{array}$ \\
\hline \multicolumn{5}{|l|}{ Age } \\
\hline $20-29$ & $110(44.3)$ & 138(55.7) & \multirow{2}{*}{\multicolumn{2}{|c|}{1.00}} \\
\hline $30-39$ & 73(53.7) & $63(46.3)$ & & \\
\hline $40-49$ & $16(80 \%)$ & $4(20)$ & 10.86) & $20.507)$ \\
\hline \multicolumn{3}{|l|}{ Work-experience(yrs.) } & \multirow{3}{*}{$\begin{array}{l}5.02(1.63- \\
15.44)\end{array}$} & \multirow{2}{*}{$\begin{array}{l}2.909(0.461- \\
18.372)\end{array}$} \\
\hline $0.5-5 y r$ & $127(46.2)$ & 148(53.8) & & \\
\hline $6-10 y r$ & $44(48.4)$ & $47(51.6)$ & & \multirow{3}{*}{$\begin{array}{l}3.102(0.357- \\
26.933)\end{array}$} \\
\hline 11-15yr & 19(70.4) & $8(29.6)$ & 1.00 & \\
\hline$>15 y r s$ & $9(81.8)$ & 2(18.2) & $4.8(0.98-23.49)$ & \\
\hline \multicolumn{2}{|l|}{ Marital status } & $91(45.5)$ & \multirow{2}{*}{$\begin{array}{l}5.24(1.13- \\
24.72)\end{array}$} & \multirow{2}{*}{$\begin{array}{l}3.160(0.306- \\
32.622) \\
2.754(0.263- \\
28.843)\end{array}$} \\
\hline Single & $90(44.1)$ & $114(55.9)$ & & \\
\hline Dependent family & & & $\begin{array}{l}1.517(1.027- \\
2.246)\end{array}$ & \multirow{3}{*}{$\begin{array}{l}0.734(0.425- \\
1.268)\end{array}$} \\
\hline Have & 107(56.3) & $83(43.9)$ & \multirow{2}{*}{1.00} & \\
\hline Not have & $92(43)$ & 122(57) & & \\
\hline \multicolumn{3}{|l|}{ Job satisfaction } & $\begin{array}{l}2.186(1.469- \\
3.254)\end{array}$ & \multirow{3}{*}{$\begin{array}{l}1.908(1.142- \\
3.188)\end{array}$} \\
\hline Dissatisfied & $55(28.4)$ & 139(71.6) & \multirow[t]{2}{*}{1.00} & \\
\hline Satisfied & $144(68.6)$ & $66(31.4)$ & & \\
\hline \multicolumn{3}{|c|}{$\begin{array}{l}\text { Autonomy and professional } \\
\text { opportunity }\end{array}$} & 1.00 & \\
\hline Dissatisfied & $67(34.4)$ & $128(65.6)$ & 5.514(3.598- & \\
\hline $\begin{array}{l}\text { Satisfied } \\
\text { Support }\end{array}$ & 132(63.2) & $77(36.8)$ & 8.451) & $\begin{array}{l}6.539(2.774- \\
15.413)\end{array}$ \\
\hline Dissatisfied & & & & \\
\hline
\end{tabular}




\begin{tabular}{|c|c|c|c|c|}
\hline Satisfied & $60(34.7)$ & $113(65.3)$ & 1.00 & \\
\hline Relation and interaction & $139(60.2)$ & $92(39.8)$ & $\begin{array}{l}3.275(2.178- \\
4.924)\end{array}$ & \multirow{3}{*}{$\begin{array}{l}1.371(0.788- \\
2.383)\end{array}$} \\
\hline Dissatisfied & & & & \\
\hline Satisfied & $88(41.9)$ & $122(58.1)$ & \multirow{3}{*}{$\begin{array}{l}1.00 \\
2.845(1.89- \\
4.284)\end{array}$} & \\
\hline Pay and benefits & $111(57.2)$ & $83(46.8)$ & & \multirow[b]{2}{*}{$\begin{array}{l}0.669(0.338- \\
1.322)\end{array}$} \\
\hline $\begin{array}{l}\text { Dissatisfied } \\
\text { Satisfied }\end{array}$ & $58(33.5)$ & $115(66.5)$ & & \\
\hline Organizational commitment & $141(60.6)$ & $90(39.4)$ & 1.00 & \\
\hline Overall commitment & & & $\begin{array}{l}1.854(1.249- \\
2.752)\end{array}$ & \multirow[b]{2}{*}{$\begin{array}{l}0.627(0.358 \\
1.099)\end{array}$} \\
\hline Low & & & & \\
\hline mign & & & 1.00 & \multirow{4}{*}{$\begin{array}{l}1.269(0.690- \\
2.334)\end{array}$} \\
\hline Affective commitment & $86(42.2)$ & 118(57.8) & \multirow{3}{*}{$\begin{array}{l}3.106(2.058- \\
4.689)\end{array}$} & \\
\hline Low & $113(56.5)$ & $87(43.5)$ & & \\
\hline High & & & & \\
\hline Continuance commitment & $93(43.1)$ & 123(56.9) & & \\
\hline Low & $106(56.4)$ & $82(45.6)$ & & \\
\hline High & & & 1.00 & \\
\hline Normative commitment & $93(43.9)$ & $119(56.1)$ & \multirow{2}{*}{$\begin{array}{l}1.782(1.202- \\
2.643)\end{array}$} & \\
\hline Low & $106(55.2)$ & $86(44.8)$ & & $\begin{array}{l}0.301(0.127- \\
0.713)\end{array}$ \\
\hline \multirow[t]{8}{*}{ High } & & & \multirow{3}{*}{$\begin{array}{l}1.00 \\
1.71(1.152- \\
2.537)\end{array}$} & \\
\hline & $55(34.6)$ & 104((65.4) & & \\
\hline & $144(58.8)$ & $101(41.2)$ & & $\begin{array}{l}1.48(0.821- \\
2.667)\end{array}$ \\
\hline & & & 1.00 & \\
\hline & & & $\begin{array}{l}1.577(1.065- \\
2.337)\end{array}$ & \\
\hline & & & & $\begin{array}{l}1.103(0.613- \\
1.986)\end{array}$ \\
\hline & & & 1.00 & \\
\hline & & & $\begin{array}{l}2.696(1.782- \\
4.079)\end{array}$ & $\begin{array}{l}3.617(1.879- \\
6.963)\end{array}$ \\
\hline
\end{tabular}


* variables which are significantly associated with the outcome variable at p-value $<0.05,1$ is the reference category; à= divorced, widowed and separated.

\section{Figures}

\section{Intent to stay in nursing profession among nurses}

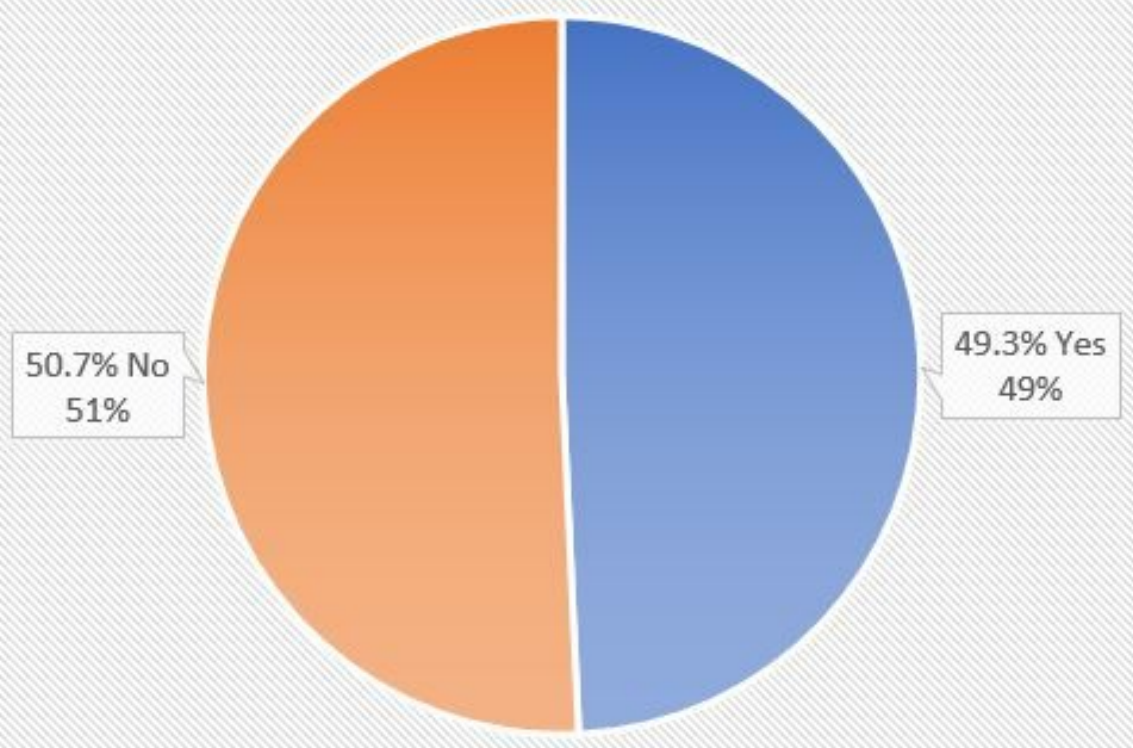

- $49.3 \%$ Yes

$=50.7 \%$ No

\section{Figure 1}

level of intent to stay in nursing profession and predictors among nurse working at public hospitals of Harari region and Dire Dawa administration eastern Ethiopia 2020. 